\title{
Analyzing Precipitation Climatology; and Past and Future Variation Trends in Precipitation and Temperature of Arba Minch and Chencha Districts, Gamo Highlands, Ethiopia (for the period 1981-2100)
}

\author{
Markato Markos \\ Mettu University, Bedele College of Agriculture and Forestry, Ethiopia \\ P.O. Box 318, Bedele, Ethiopia
}

\begin{abstract}
Global climate is changing significantly causing changes in the climatic variables especially, precipitation and temperature. This study was conducted to analyze the change in precipitation and temperature in two Arba minch and Chencha districts, Southern Ethiopia. Daily observed rainfall, maximum and minimum temperature data were collected from the Ethiopian National Meteorological Agency for the years 1981 to 2018. The data from the Climate Hazards Center Infrared precipitation with Station (CHIRPS) was used to fill the missing data. REMO2009, a regional climate model (RCM), was used to extract daily rainfall and temperature data for the period 1981-2100, two representative concentration pathways: RCP4.5 and RCP8.5 were used for the projection. The model data was corrected according to the observation prior to analysis. The results revealed that the study area has bimodal rainfall characteristics with the peaks in April and October of the first and second main rainy seasons respectively. In a decadal time period, there is a shift in the peak of precipitation during the first main rainy season, indicating seasonal shift. The total rainfall received over a decadal time period also varies significantly. In terms of future projections, seasonal rainfall peaks will remain similar on average, but total rainfall will continue to be highly variable. The projection also show that the second main rainy season for both stations will vanish completely by the end of the century, resulting in mono-modal rainfall characteristics.
\end{abstract}

Keywords: Climate Change, Regional Climate Models, representative concentration pathways

DOI: $10.7176 / \mathrm{JEES} / 11-7-03$

Publication date:July $31^{\text {st }} 2021$

\section{Introduction}

\subsection{Background}

Global climate has changed and also is changing in a very dramatic rate of change. The change in a global climate exposes a significant impact on the environment and on social and economic well-being (IPCC, 2007). Temperature and rainfall are the most commonly used variables in order to show climate of an area. An increase in air temperature and variability in precipitation and their impacts on various fields and sectors are highly evident in different parts of the world. Agriculture is one of the most vulnerable sectors to climate change; hence, the areas which depend on agricultural activities will be highly affected by the changing climate. Africa, particularly Ethiopia most (80\%) of the population depend on agricultural products (Deressa et al., 2009). Therefore, they are highly affected by climate change (Solomon et al., 2019). Moreover, people in Gamo highlands in SNNPR regional state, depend on rain-fed agricultural activities which uses natural rainfall, which makes them very vulnerable for the changing climate impacts (Teyso and Anjulo, 2016).

Many studies show that rainfall and temperature are changing but varying trends for different areas. Amogne A., et al., (2018) have found that annual and kiremt rainfall show significantly declining trend in Ethiopia, but the belg rainfall decline is insignificant. Regarding temperature, mean and minimum temperature increased significantly while the maximum temperature shows insignificant increase (Amogne A. et al., 2018). In Gamo Gofa Zone, Tefera and Agena investigated and found that, most of the land area of the zone had experienced insignificant variation trends for both annual and seasonal rainfalls. Mean annual and seasonal maximum temperature in the zone showed warming trends. Significant land of the zone had experienced both warming and cooling trends of minimum temperature for annual and seasonal timescales (Teyso and Anjulo, 2016; Seleshi, 2004).

While many studies including the above listed, exploring the trend of variation in temperature and precipitation, it is visible that the trends vary from place to place (NMA, 2007). So that, it is important to characterize and analyze the climate and variation trend for a small area to get exact climatological characteristics and variation trends of an area. In addition, most of the previous studies used only station data, which is only available for a very small period (maximum of 5 years) of time in the study areas; hence it is difficult to characterize the climate and variation trends of the areas. Therefore, this study aims to analyze the climatology and variation trends of precipitation and temperature by filling the missing data from CHIRPS in Arbaminch and Chencha districts, Gamo, Ethiopia. The study also will try to show the future trends of climate in 
the study areas by extracting projected output from Climate projections from the regional climate model REMO2009. The regional climate model (RCM) REMO2009 is used to downscale global simulations of the Max Planck Institute for Meteorology-Earth System Model MPI-ESM. REMO is a limited-area threedimensional atmospheric circulation model. It is based on the 'Europa-Modell' of the German Weather service and on the physical parameterizations of the global three-dimensional atmospheric circulation model ECHAM-4. Daily rainfall, maximum and minimum temperature data were extracted for the period 1981-2100 under the two representative concentration pathways: RCP4.5 and RCP8.5.

\subsection{Research Objectives}

The objectives of the study was:

$\checkmark$ To analyze the temporal variation trends in precipitationbin Arbaminch and Chencha Districts

$\checkmark \quad$ To identify the general precipitation meteorological characteristics of Arbaminch and Chencha Districts

$\checkmark \quad$ To predict future trends in the study area

\section{Data and Methodology}

\subsection{Study Area}

The study was conducted in Gamo zone of Southern Nations, Nationalities and Peoples' Regional State, Southwestern Ethiopia, about $250 \mathrm{Km}$ from the regional capital Hawassa and about $430 \mathrm{~km}$ south of Addis Ababa. It is geographically located between $5^{\circ} 37^{\prime}$ to $6^{\circ} 42^{\prime} \mathrm{N}$ and $36^{\circ} 23^{\prime}$ to $37^{\circ} 56^{\prime} \mathrm{E}$ and between $517 \mathrm{~m}$ and $4207 \mathrm{~m}$ above sea level. The following figure shows the map of the study area.

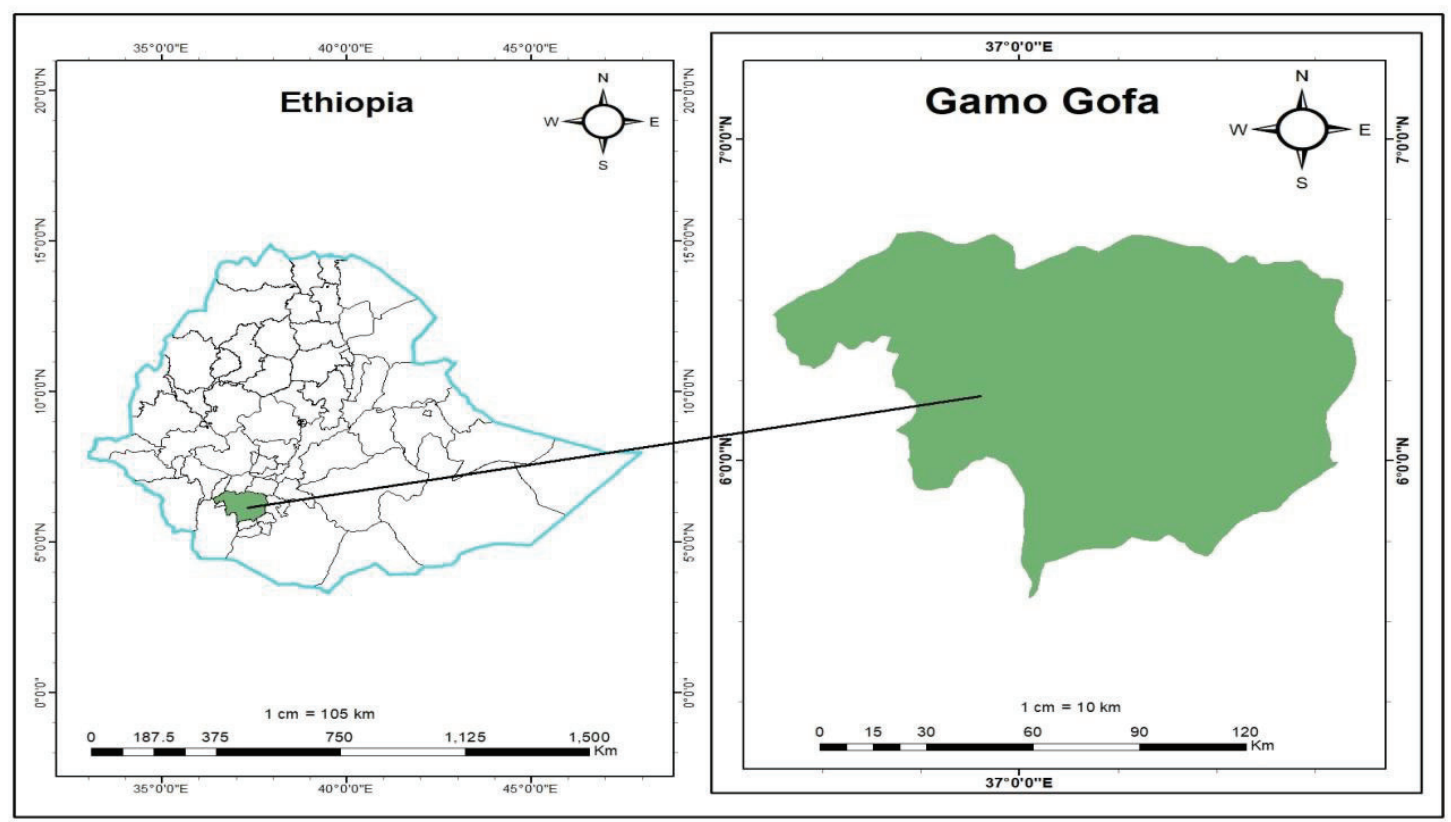

Figure 1: Study Area Map

\subsection{Data used and available data}

Both observation and model data were used. Daily observed rainfall, maximum and minimum temperature data were collected from National Meteorological Agency of Ethiopia for the two stations for a period 1981-2018. The missing data was filled by the data from CHIRPS data from Climate Hazards Center Infrared precipitation with Station website. The table below (table 1) shows the station information and available data.

Model data were extracted from the regional climate model (RCM), REMO2009. Daily rainfall and temperature data were extracted for the period 1981-2100 under the two representative concentration pathways: RCP4.5 and RCP8.5.

Table 1: station information

\begin{tabular}{|l|l|l|l|l|l|l|}
\hline Station & Location & \multicolumn{2}{c|}{ \%Data available } & \multicolumn{2}{c|}{ \%missing data } \\
\hline & Lon $\left.^{\circ}\right]$ & Lat $\left[{ }^{\circ}\right]$ & precipitation & temperature & precipitation & temperature \\
\hline Arbaminch & $37^{\circ} 6^{\prime}$ & $6^{\circ} 1^{\prime}$ & 83.4 & 68.5 & 16.6 & 31.5 \\
\hline Chencha & $37^{\circ} 37^{\prime} 47^{\prime}$ & $6^{\circ} 13^{\prime} 55^{\prime}$, & 59.25 & 16.2 & 40.75 & 83.8 \\
\hline
\end{tabular}




\subsection{Data analysis}

The station observation data filled from CHIRPS for its missing data was analyzed to show the historical trend for the period 1981-2018. Precipitation data was used in a decadal range to analyze the seasonal variation trend by finding monthly mean rainfall for 10 years. The analyzed future time periods extend from 2006-2040 for short-term, 2041-2070 for the mid-century and from 2071-2100 for the end of the century. Precipitation data was analyzed by finding monthly mean for 34, 29 and 29 years for short term, mid-century and end of century time periods respectively. The temperature data for the projection was analyzed by calculating annual mean temperature from 2006-2100 time periods for both RCP's.

\subsection{Bias Correction}

Statistics of precipitation and temperature projections supplied by climate models in the control period do not usually fit exactly those of observations in the same period. Such errors may affect simulated flow results in the future period. Bias correction methods try to improve the fitting of climate model simulations to observations in the control period, in order to enhance the reliability of climate model results in the future period (Enrique S., et al 2019). In this study, temperature and precipitation series have been corrected separately with the following methodologies. Daily precipitation data was corrected by using power transformation method and temperature by using linear scaling method with the formula as follows:

$$
\mathbf{P}_{\text {corr }}=\mathbf{a} * \mathbf{P}_{\text {mod }}{ }^{b} \text {...................for precipitation (Turco, M. et al.,2017) }
$$

Where, Pcorr is the corrected precipitation, Pmod is the original precipitation extracted from the model, $b$ is the exponent in month $\mathrm{m}$ and scaling factor (a) is calculated to establish that corrected precipitation amounts are equal to the observations.

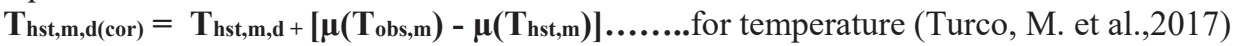

Where, Thst,m,d(cor) denote the corrected temperature on the dth day of the mth month, Thst,m,d denote the temperature from original RCM output during the relevant period; the subscripts $\mathrm{d}$ and $\mathrm{m}$ are specific days and months, respectively; and $\mu$ denotes the mean value.

\section{Result and discussion}

\subsection{General Meteorological Characteristics (precipitation)}

The figure below shows the monthly mean rainfall data for both Arba Minch and Chencha stations from station observation and RCM REMO2009 for the period 1981-20018.
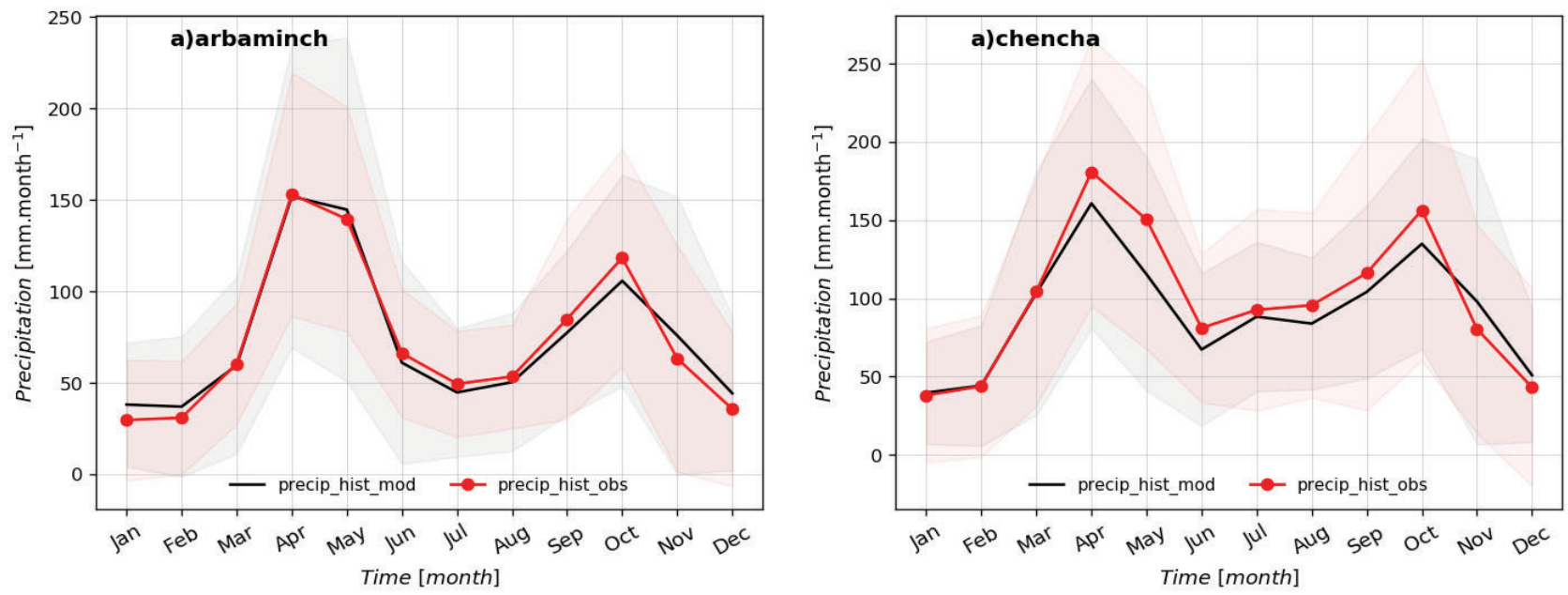

Figure 2: Mean monthly precipitation (1981-2018)

Both stations have bimodal rainfall characteristics with the peaks April and October of the first and second main rainy seasons respectively. Generally Chencha gets higher rainfall throughout the year than Arba Minch. Station observation and the model output are almost similar for Arba Minch while, a little higher observed rainfall than the model output for Chencha.

\subsection{Seasonal Variation Trends in Precipitation}

The following figures (figure 4) show the seasonal variation trends in precipitation in a decadal range. 80, 90, 20, and 2011 representing 1981-1990, 1991-2000, 2001-2010, and 2011-2018 time ranges respectively. The variation trend can be seen from the peak of the rainy seasons and from the amount of rainfall received. 

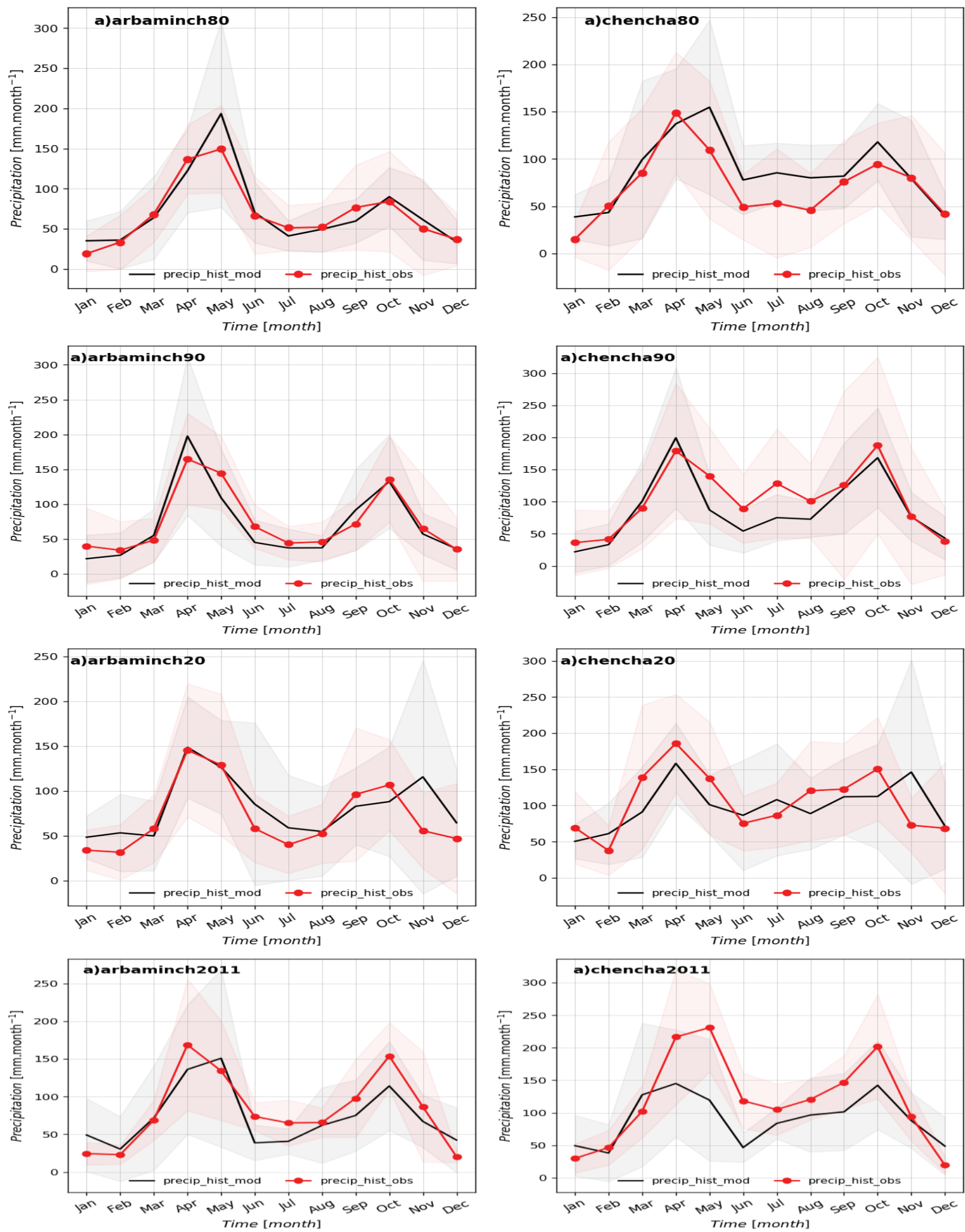

Figure 3: Seasonal Precipitation Variation Trend

The peak of the first main rainy season shifted from May to April from 80's to 90's for Arba Minch but, for Chencha, it was in April until the recent decade and shifted to May in this decade. The amount of rainfall received decreased from $200 \mathrm{~mm}$ at the peak of the first main rainy season in the first two decades to nearly $150 \mathrm{~mm}$ in the last two recent decades for Arba Minch. But for Chencha, it increased from $150 \mathrm{~mm}$ to $250 \mathrm{~mm}$ from the first to the recent decade.

The second rainy season has no shift in the peak but it varies significantly in the amount of rainfall received. 
It has increased from less than $100 \mathrm{~mm}$ in 80 's to $150 \mathrm{~mm}$ in 90 's and it further decreased to $100 \mathrm{~mm}$ in 2000 's and increased to more than $150 \mathrm{~mm}$ in the recent decade for Arba Minch. For Chencha too, the trend is similar but the amount is higher.

\subsection{Future projections}

\section{i. Precipitation}

The figures below, displays the short term (top), mid-term (middle) and long term projections of precipitation for the study areas extracted from RCM REMO2009.
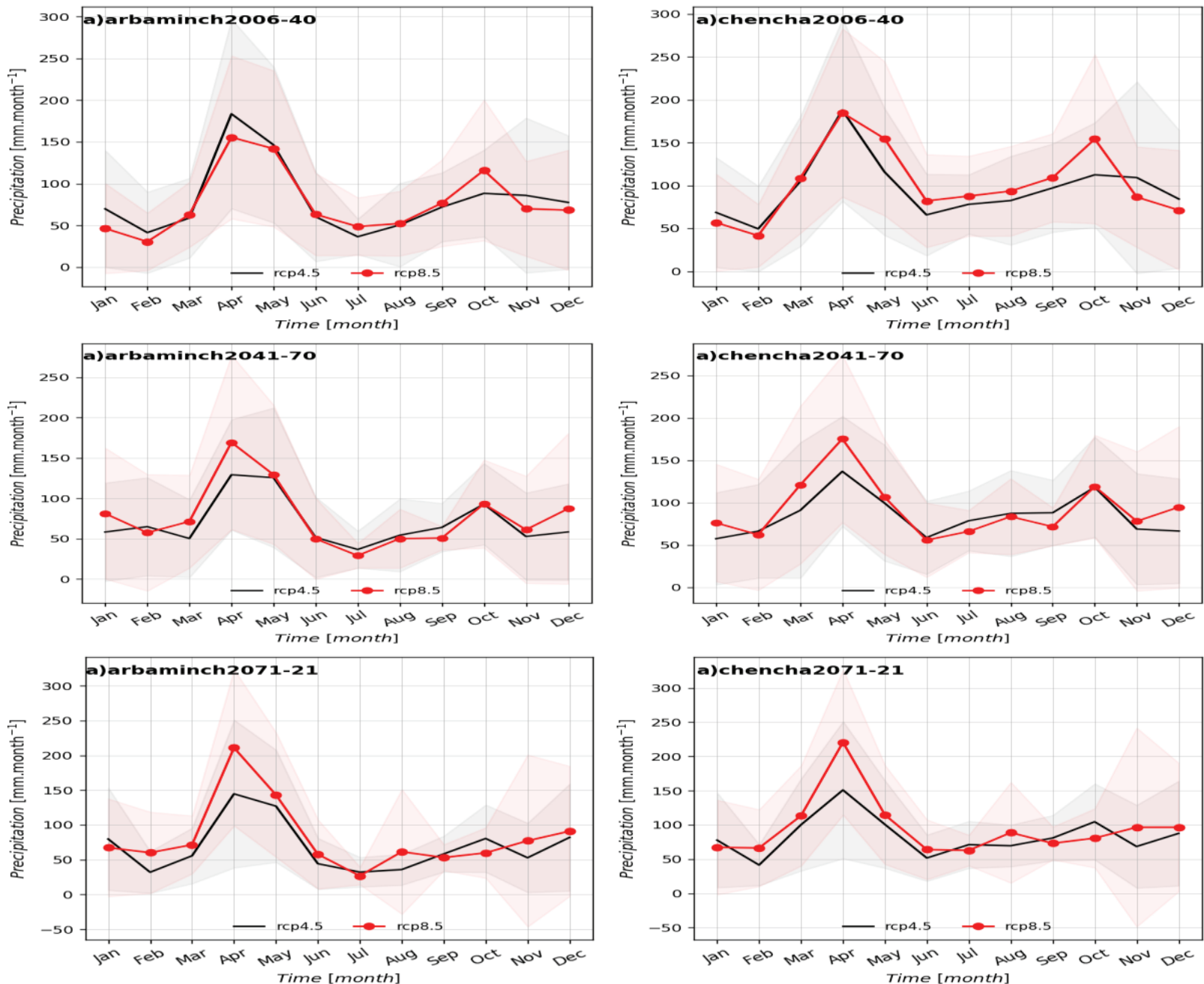

Figure 4: Projected future precipitation

Both stations show that, the amount of rainfall received will decrease from the recent state in short term (2006-2040) and mid-term (2041-2070) projections, while there will be an increase in the long term (2071-2100). The projection also shows the stations will have only one rainy season at the end of this century with the peak in April for both RCP's.

ii. Temperature

The following figure shows the projected temperature for Arba Minch station for both RCP's. I haven't projected for Chencha, because both stations are located in the same grid, and the observed temperature data for Chencha I have is too small to correct the bias of the model. 

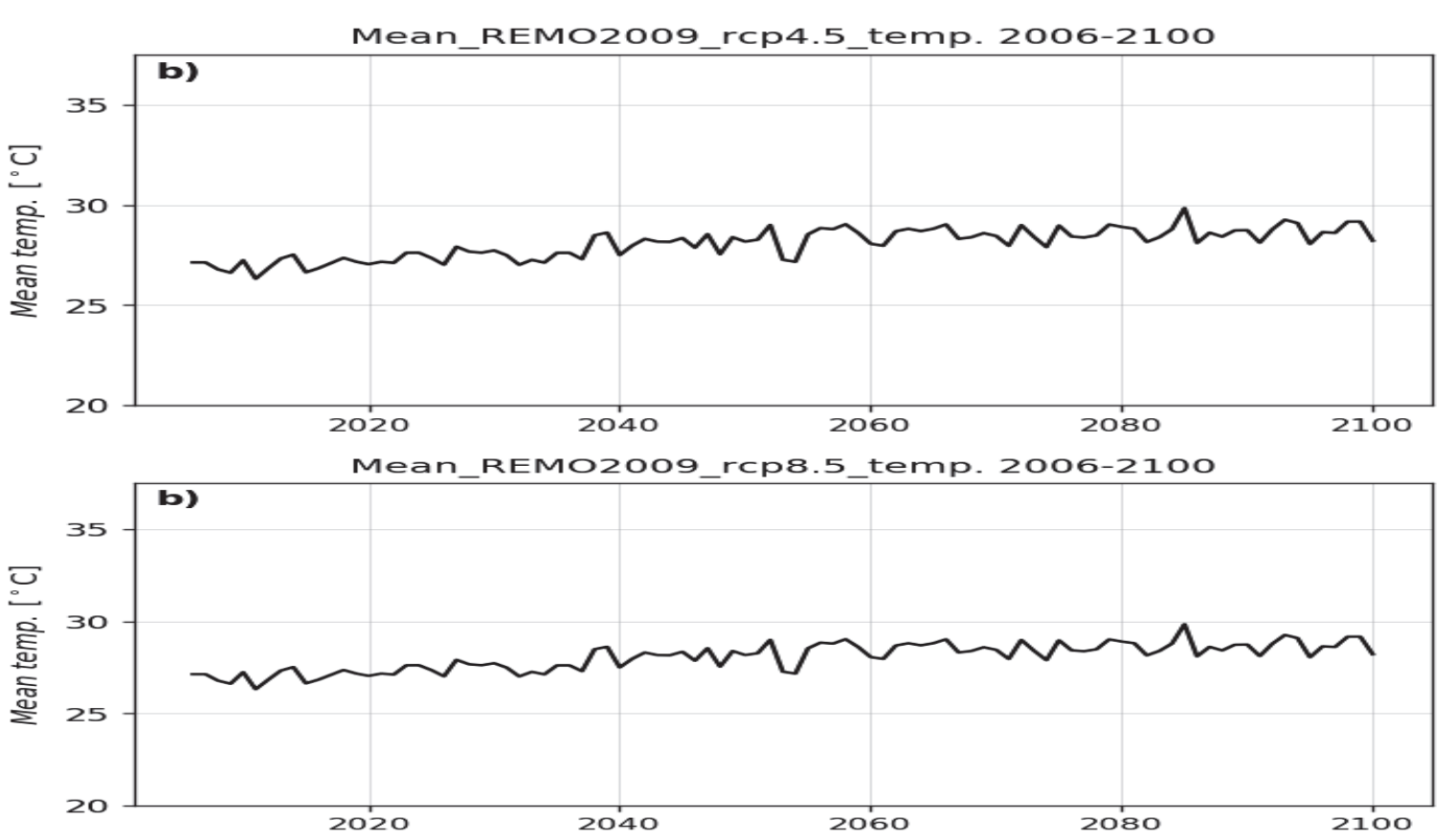

Figure 5: Projected future Temperature

The temperature projection shows a significant increase in mean temperature at the end of the century, nearly $290 \mathrm{C}$ in 2100 , while it is around $270 \mathrm{C}$ now. It shows similar trend in both rep4.5 and 8.5.

\section{Conclusion}

In this study the seasonal variation trends in precipitation was investigated by using station observation and climate model data for 37 years; and the future projected precipitation and mean temperature trends for the study areas selected. The global simulations have been downscaled with REMO2009 regional climate model.

The results show that the study areas have two main rainy seasons with the peaks in April and October in average. The analysis indicated that there is a shift in the peak of the precipitation in the first main rainy season in a decadal time period, which indicates seasonal shift. It also have been seen that there is a significant variability in the amount of total rainfall received in a decadal time period. In terms of future projections, the peaks of seasonal rainfall will remain similar on average, but the total amount of rainfall received will continue with high variability. The projection also depicts that the second main rainy season will vanish totally at the end of the century for both stations, so that, the rainfall characteristics of the areas will be mono-modal.

There will be significant increase in mean temperature at the end of the century. The mean temperature is projected to increase by $20 \mathrm{C}$ compared to the period prior to 2005 .

\section{References}

Amogne Asfaw, Belay Simane, Ali Hassen, Amare Bantider. (2018). Variability and time series trend analysis of rainfall and temperature in northcentral Ethiopia. Weather and Climate Extremes.

Deressa TT, Hassan RM, Ringer C., (2009). Assessing household vulnerability to climate change: The case of farmers in the Nile basin of Ethiopia. IFPRI Discussion Paper 00935. International Food Policy Research Institute;

Enrique S. , Luis M. and Carlos G. (2019). Selection of Bias Correction Methods to Assess the Impact of Climate Change on Flood Frequency Curves

IPCC. (2007). Climate Change; The Physical Science Basis.

National Meteorological Agency of Ethiopia, (2007). Climate Change National Adaptation Programme of Action (NAPA) of Ethiopia. Addis Ababa, Ethiopia.

Seleshi Y, Zanke U., (2004) Recent changes in rainfall and rainy days in Ethiopia. International Journal of Climatology.;24:973-983.

Solomon H. Gebrechorkos; Stephan Hülsmann; \& Christian Bernhofer. (2019). Long-term trends in rainfall and temperature using high-resolution climate datasets in East Africa. nature research.

Tefera Ashine Teyso; Agena Anjulo. (2016). Spatio-temporal Variability and Trends of Rainfall and Temperature Over Gamo Gofa Zone, Ethiopia. Journal of Scientific Research \& Reports.

Turco, M.; Llasat, M.C.; Herrera, S.; Gutiérrez, J.M. (2017) Bias correction and downscaling of future rcm precipitation projections using a mos-analog technique. J. Geophys. Res. Atmos., 122, 2631- 2648 